\title{
FLOOD HAZARD MAPPING AND VULNERABILITY ANALYSIS OF BISHNUMATI RIVER, NEPAL
}

\author{
Susheel Dangol, Arnob Bormudoi
}

Keywords: Flood, Hazard, Vulnerability, Bishnumati River, HEC-RAS, HEC-GeoRAS

\begin{abstract}
Flood is one of the striking water induced disaster that hits most of the part of the world. In Nepal also it is one of the serious disasters which affect the human lives and huge amount of property. The increase of population and squatter settlements of landless people living at the bank of the river has tremendous pressure in encroachment of flood plain making them vulnerable to the flood damage. The study describes the technical approach of probable flood vulnerability and flood hazard analysis. Bishnumati catchment was taken as area of study. One dimension model of HEC-RAS with HEC-GeoRAS interface in co-ordination with ArcGIS was applied for the analysis. Analysis shows that the flood area increases with flood intensity. Higher flood depth increases and lower flood depth decreases with increase in intensity of flood. Inundation of huge area of urban land indicates that in future human lives are more prone to flood disaster. Thus, the study may help in future planning and management for future probable disaster.
\end{abstract}

\section{INTRODUCTION:}

Water induced disasters of varying intensity and magnitude affect various parts of Nepal regularly. The principal triggering factor is the monsoonal rainfall which is mostly confined between June and September every year (Chalise, et. al. 1995). About $80 \%$ of annual rainfall occurs during monsoon season and thus, extreme floods during monsoon season occur due to this concentrated spells of heavy rainfall (Shakya, 1998).

The draining of natural wetlands and the spread of towns across the countryside and many other human interventions has reduced infiltration leading to more frequent and higher floods (Shakya, et. al., 2006). Such changes are also observed in the Kathmandu Valley. Based on reported floods in Kathmandu valley (Table 1), it can be said that the valley is susceptible to severe floods. Hence proper flood forecasting and awareness system is quite necessary in order to minimize the probable loss due to floods.

In most of the urban cities of Nepal, floodings are due to the combination of extreme rainfall and urbanization. However, issue of urban flooding was highlighted when Katmandu got flooded in 2002 with total human death of 27 . Most of the rivers were flooded with huge loss of property. The major cause of the flooding was the constriction of river channel for the human settlement.

Flood forecasting and warning is one of the most important non structural measures in comprehensive flood loss prevention and management (Lin, 1995). Thus flood forecasting is very important for efficient means of minimizing flood damage and loss of life. It should be an integral part of flood control system and must deserve prominent place in the national flood policy (Singh and Singh, 1988).

Among various non structural measures needed for disaster mitigation, hazard mapping is one of the important nonstructural measures (Mahato, et. al., 1996). Land flood hazard areas can be delineated based on hydrologic studies for selected flood peak magnitudes and topographic information (Joshi, 1987).

2. STUDY AREA:

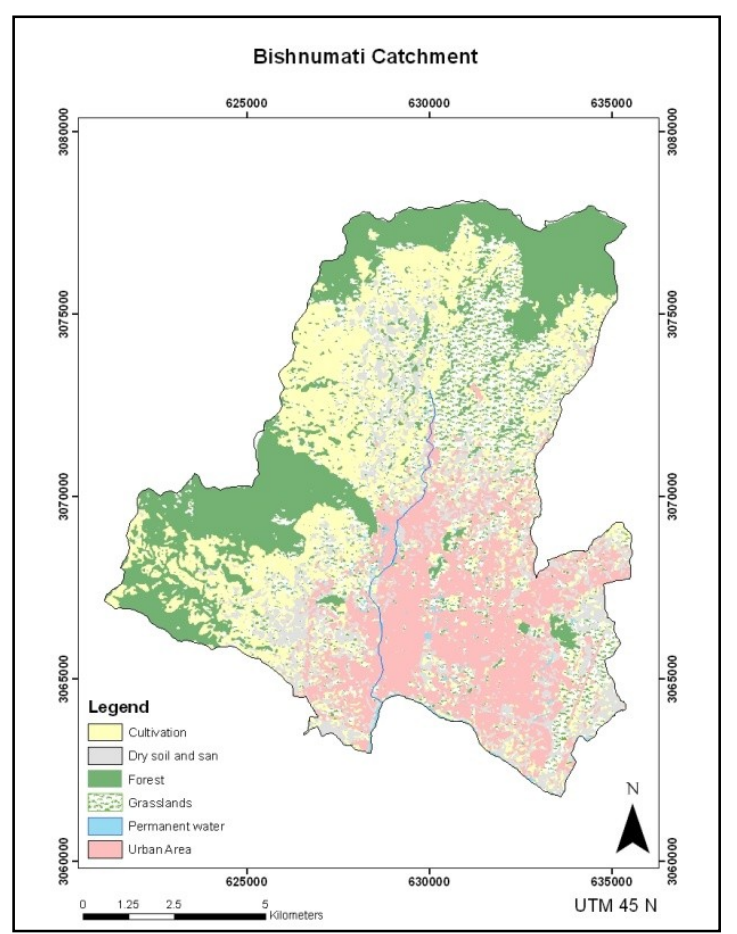

Figure 1: Land use map of study area (from ALOS Avnir-2) 
Bishnumati catchment with the outlet at confluence of Bishnumati and Bagmati river of Kathmandu is taken as the study area. The the upstream of the catchment consist of cultivation and forest area and the downstream is more densly populated. Further, the channel of the river is modified by differnt artifical levees, which effects the flow of water in the river. Since the northen face of the valley receives more intense rainfall, there is the probability of flood disaster due to human intervension in the natural flow of river channel. Due to this reason, the catchment was selected as study area.

\section{OBJECTIVES:}

The main objective of this study study is to estimate flood hazard mapping in a GIS environment. The specific objective of this study includes:

- Flood frequency analysis

- Flood vulnerability mapping

\section{DATA USED:}

The data used in this study are-

\section{Hydrologic data-}

- DEM generated from free ASTER image in the Bishumati River Catchment. Spatial resolution 30x30 m.

- Daily maximum river discharge data for the upstream and the downstream gauge stations for a period of 30 years collected from Department of Hydrology and Meteorology.

\section{Satellite data-}

- ALOS AVNIR2 image of the study area of December 14, 2008

\section{GIS data - (from survey department)}

- Municipal boundary

- Road Network

- River Network

- Building Footprints

Other data-

- Population Census data per village level 2001 from Central Bureau of Statistics

- Cross sections along the river channel created by the HEC-geoRAS

\section{METHODOLOGY:}

1d flood model HEC RAS V4.0 has been used for calculation of one-dimensional water surface elevations/profiles for flood level prediction for different return periods. HEC-geoRAS has been used as an interface between HEC-RAS and the GIS environment. Stream lines were generated from the ASTER DEM using HEC-Geo HMS. This stream line was given as one of the input to the 1D model HEC RAS. Frequency analysis was carried out on the peak annual discharge data at the upstream as well at the downstream gauge station. The values obtained from Gumbell distribution was chosen as the hydraulic parameter for input to HEC RAS. The land use map was utilized for assigning Manning's roughness coefficient values to the model input.

\begin{tabular}{lll} 
Table & 1: $\begin{array}{c}\text { Manning's roughness coefficient for } \\
\text { different land use. }\end{array}$ \\
\hline S. & Land use type & $\begin{array}{l}\text { Manning's } \\
\text { Coefficient }\end{array}$ \\
No. & & 0.035 \\
\hline 1 & Cultivation & 0.015 \\
2 & Built-up area & 0.15 \\
3 & Forest & 0.029 \\
4 & Dry soil and Sand & 0.04 \\
5 & Permanent water &
\end{tabular}

This manning's $\mathrm{n}$ value was assigned as taken from HEC RAS hydraulic reference manual (2002) for different land use types within the study area (Table 1). Geometric data editing was carried out in HEC RAS to fit the surveyed cross sections to the model. Table 2 shows the values obtained from the frequency analysis of the 30 years discharges at the upstream and downstream.

Table 2: Discharge values for different return periods.

\begin{tabular}{ll|lc}
\hline \multirow{2}{*}{ S.No. } & Return & \multicolumn{2}{|c}{ Discharge } \\
\cline { 3 - 4 } & Period & Upstream & Downstream \\
\hline 1 & 10-year & 3 & 456 \\
2 & 20-year & 4 & 531 \\
3 & 50-year & 4 & 628 \\
4 & 100-year & 5 & 701 \\
\hline
\end{tabular}

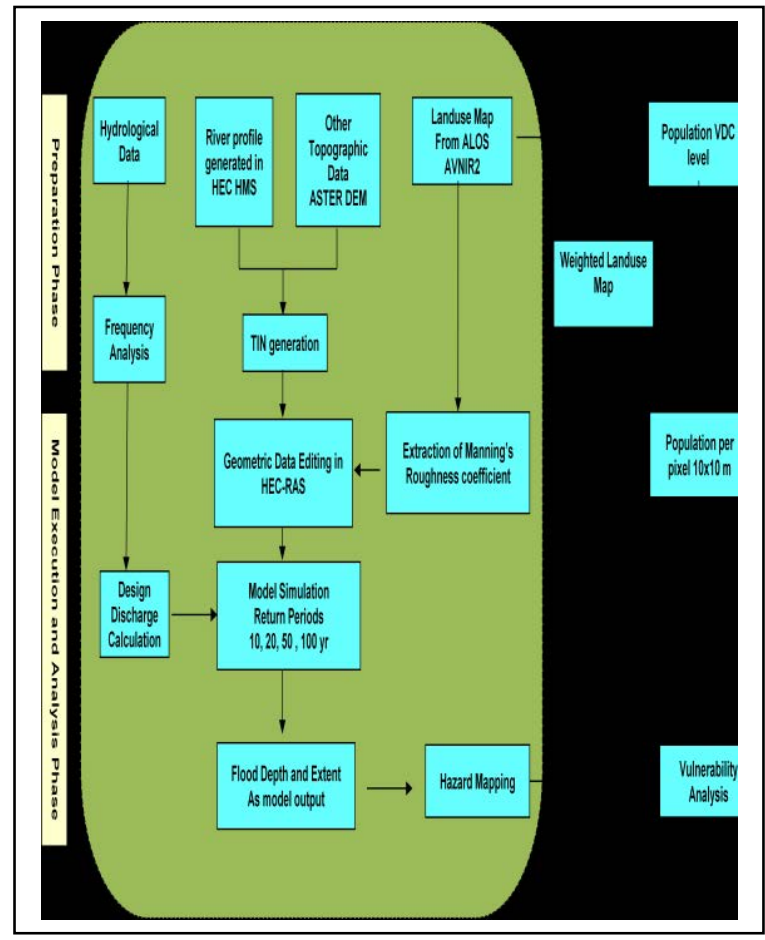

Figure 2: Methodology. 
Post processing included creating maps of inundation in the GIS platform and the vulnerability analysis. Vulnerability analysis was done on investigate the physical vulnerability of the population and the landuse to the floods.

For this, the population was distributes in the study area according to the weightage given to the landuse. Three maps of depth, population density and landuse were used to make the final vulnerability map after assigning proper weighatage.

\section{RESULTS AND DISCUSSION:}

The inundation map shows the variation in flood depth over the flood plain. The inundation maps provide qualitative picture of the depth and aerial extent of inundation coverage.

\section{FLOOD VULNERABILITY}

The flood vulnerability maps for the area were prepared by intersecting the land use map of the floodplain with the flood area polygon for each of the flood event being modeled. The assessment of the flood area shows that most of vulnerable area lies on the urban land which shows the considerable impact of flooding on the human beings. Another effected area includes cultivation area.

Table 3: Land use vulnerability for different return periods.

\begin{tabular}{l|llll}
\hline \multirow{2}{*}{$\begin{array}{l}\text { Land } \\
\text { class }\end{array}$} & \multicolumn{4}{|l}{ Area in Hectares } \\
\cline { 2 - 5 } & $10 \mathrm{yr}$ & $20 \mathrm{yrs}$ & $50 \mathrm{yr}$ & $100 \mathrm{yr}$ \\
\hline Cultivation & 22.3 & 23.8 & 25.4 & 26.4 \\
$\begin{array}{l}\text { Dry soil and } \\
\text { sand }\end{array}$ & 46.6 & 48.6 & 51.0 & 52.7 \\
Forest & 0.4 & 0.4 & 0.6 & 0.7 \\
Grassland & 13.2 & 14.0 & 15.1 & 16.2 \\
Urban area & 153.2 & 163.2 & 176.7 & 185.7 \\
\hline Total & 235.5 & 250.7 & 268.8 & 281.6 \\
\hline
\end{tabular}

Similarly tabel 4 shows the total buildings vulnerable due to different frequency of floods.

Table 4: Total buildings vulnerable to the flood.

\begin{tabular}{|c|c|c|c|c|c|}
\hline & $\begin{array}{l}\text { Affec } \\
\text { Deptl }\end{array}$ & $\begin{array}{l}\text { d } B \\
\text { Class }\end{array}$ & $\begin{array}{l}\text { ildings } \\
\text { m) }\end{array}$ & per & $\begin{array}{l}\text { Total } \\
\text { Buildings }\end{array}$ \\
\hline $\begin{array}{l}\text { Magnitude } \\
\text { of flood }\end{array}$ & $\begin{array}{l}(0- \\
0.5)\end{array}$ & $\begin{array}{l}(0.5- \\
1.5)\end{array}$ & $\begin{array}{l}(1.5- \\
2.5)\end{array}$ & $>2.5$ & \\
\hline $10 \mathrm{yr}$ RP & 2065 & 1377 & 193 & 119 & 3754 \\
\hline 20 yr RP & 2082 & 1602 & 191 & 123 & 3998 \\
\hline 50 yr RP & 2115 & 1922 & 146 & 105 & 4288 \\
\hline 100 yr RP & 2123 & 2127 & 148 & 104 & 4502 \\
\hline
\end{tabular}

Table 5: Poplation vulnerability.

\begin{tabular}{llllll}
\hline 10 yr RP & 14,820 & 11,692 & 894 & 1,531 & 28,937 \\
20 yr RP & 14,701 & 13,742 & 900 & 1,639 & 30,982 \\
50 yr RP & 14,580 & 16,337 & 910 & 1,692 & 33,519 \\
100 yr RP & 14,554 & 17,980 & 942 & 1,750 & 35,226 \\
\hline
\end{tabular}

Table 5 shows total population vulnerabel based on the available population census of 2001 AD.

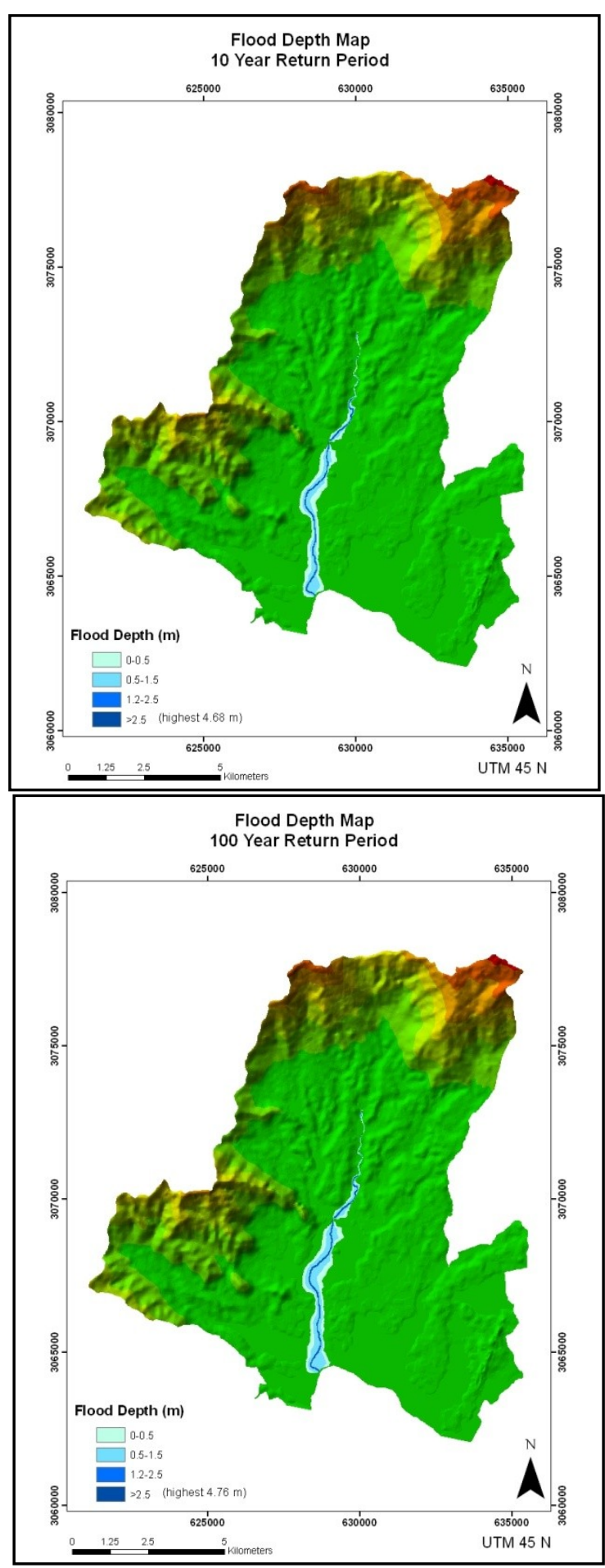

Magnitude Population affected per Depth|Total

\begin{tabular}{|c|c|c|c|}
\hline of flood & Class (m) & & \\
\hline & $\begin{array}{ll}(0.0- & (0.5- \\
0.5) & 1.5)\end{array}$ & $\begin{array}{l}(1.5- \\
2.5)\end{array}$ & $>2.5$ \\
\hline
\end{tabular}



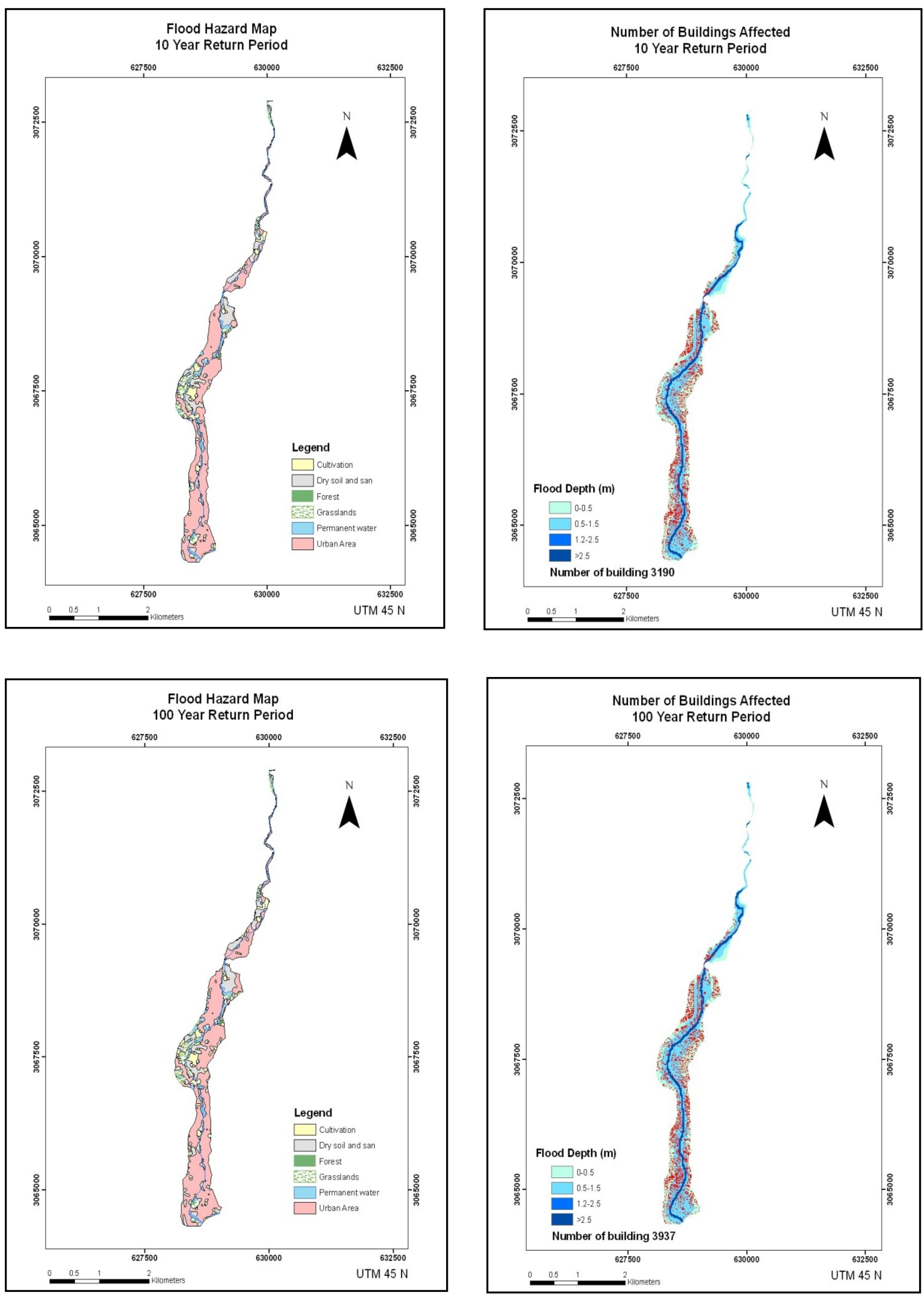


\section{CONCLUSIONS / RECOMMENDATIONS:}

The study shows the systematic process of preparation of flood vulnerability and hazard maps with the application of one dimensional model HEC RAS and ArcView with HEC-GeoRAS as interface between two. The application of this models and procedure provide effective results within less time consumption and little resources. The result obtained as graphical output (maps) from the model for different return period of flood can help in decision making.

The flood vulnerability was assessed with regard to land use pattern of the study area. It shows that huge percentage of vulnerable area lies under urban area in different flood frequencies showing considerable impact of flooding on the human beings of the area. Further, the analysis showed that maximum area under flood was between 0.5 to 1.5 meters for all the return periods.

Similarly, flood hazard assessment was also done according to different return periods. The relation between flood discharge and flooded area shows that there is increment of flooded area with increase in discharge. One of the biggest challanges remain here is the generation of the precise DEM. In this study freely available ASTER DEM of $30 \mathrm{~m}$ resolution has been used which is not sufficient for hyrological modelling in a small catchment like this.

Thus, availability of high resolution DEM is necessary to get higher accurate results. This kind of models are very useful and important for preplanning of disaster and also planning for proper land use, land developement and settlement planning.

\section{References:}

Chalise, S. R., M. L. Shrestha and R.P. Nayaju, 1995. Rainfall as The Primary Indicator of Water Induced Disasters in Nepal. Proceeding of International Seminar on Water Induced Disaster March 20-25, $\mathrm{HMG} / \mathrm{JICA}$.

Shakya, B., 1998. Problems Due to Some Severe Floods and Other Catastrophic Events Associated With Synoptic Situation in Nepal. Polish Polar Studies: 25th International Polar Symposium, Warszawa 1998, P. Glowacki and J. Bednarek (Eds.), Institute of Geophysics of the Polish Academy of Sciences. Warsazawa pg 205-213.

Shakya, B., R. Ranjit, A. Shakya and S. Bajracharya, 2006. Urban Flooding in Kathmandu Valley an flood Education of People Living at the Flood Plains. Journal of Hydrology and Meteorology 2006. Systems in the ESCAP Region. Proceeding of
International Seminar on Water Induced Disaster, March 20-25 HMG/JICA.

Singh, M. and K. N. Singh, 1988. Flood Hazards: A Perspective on Their Control, Planning and Management. Planning in Integrated Rural Environment, Singh, R. Y. Singh and A. K. Singh (Eds), Deep and Deep publication, Delhi.

Mahato, R. C., D. Higaki, T. B. Thapa and N. P. Paudyal, 1996. Hazard Mapping Based on the Few Case Studies in the Central Region of Nepal. Proceedings of An International Seminar on Water Induced Disaster, Kathmandu, Nepal 26-29 November, pg 260.

Joshi, K. N., 1987. Satellite Remote Sensing and Its Application in Flood Hazard- A Case Study in Transitional Zone (Luni Basin) of Great India.

Sharma, H. S., and M. L. Sharma, Environment Design and Development, Pg 478-484.

\begin{tabular}{|l|l|}
\hline & \\
&
\end{tabular}

